calculated over a period of several days. Current speeds were found to vary between 2 and $20 \mathrm{~cm} / \mathrm{sec}$. Subtler data from the continuous readings of the anchored buoys have yet to be analysed at Wormley. The hope is that from this initial experience a programme for immediately reducing data from the buoy recorders on board Discovery can be ready in time for the installation of a computer on board. This, it is hoped, will be working when the next deep current cruise takes place in about a year's time.

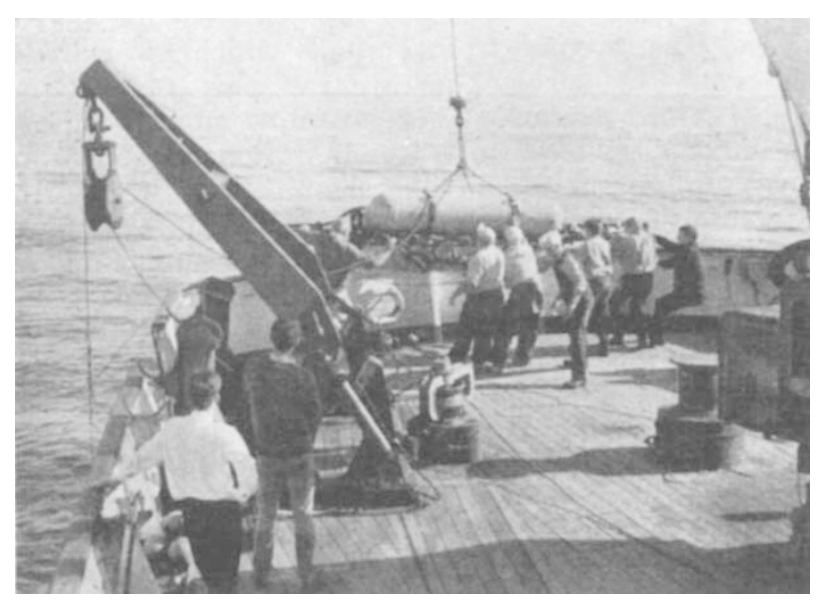

Launching a deep-sea buoy for current measurement from RRS Discovery (National Institute of Oceanography).

The ultimate object of this work is to investigate the relationship between atmospheric phenomena and deep water currents. It is expected that this interaction will be expressed as a time variation with a period of several weeks. Studies like these could eventually help with long-range weather forecasting.

\section{High off the Ground}

When Concorde made its first appearance at Toulouse on December 11, reporters and officials were dwarfed by the undercarriage, especially at the nose where the aircraft is $\mathbf{1 5 . 5} \mathrm{ft}$. off the tarmac. There are two reasons for this. Because of the delta design, the Concorde has a high landing angle, about $10^{\circ}$ nose high. And because of this high nose angle, the nose has to droop $17 \cdot 5^{\circ}$ for the pilot to be able to see out properly when landing or taxi-ing. The design of this undercarriage, however, has not presented many problems to Messier and Hispano-Suiza, who were responsible for the nose landing gear and the main landing gear respectively, as the Concorde lands at 153 knots, not much faster than the normal landing speed of subsonic jet aircraft.

Concorde's drooping nose seems to be a common factor with all supersonic airliners. The winning US design, the Boeing 2707, has one, as did the Lockheed design. The Russian TU-144, another challenger to Concorde, also has the droop nose. The Concorde project is costing the French and British governments
$£ 250$ million each. Each aircraft is expected to cost $\mathfrak{f 7} \cdot 5$ million, including initial spares.

\section{Report Justified}

NoT many compilers of annual reports seriously consider whether their labour is worthwhile. But Dr S. G. Burgess, scientific adviser to the Greater London Council's Scientific Branch, has at least tried to justify his annual report for 1966. He says it is only by collecting results of scientific studies and presenting a summary that it can be assessed whether the scientific branch is worth its keep. The report is published by the Greater London Council, price $5 s$.

According to the report, some 124,672 samples were examined during 1966 by the scientific branch. These included asphalts, tarmacadams, plasters, plastics and putties; butter, blancmange powders and suet; insecticides, paints and rubber. Items which receive most attention in the report are: water pollution and sewage treatment, building materials for construction and maintenance, environmental studies, and general supplies and services. W. B. Chapman, the public analyst, has also included a report within the main one which refers to 3,727 samples received under the Food and Drugs Act. Dr Burgess has also indicated probable lines of progress for the following year.

\section{Generating Neutrons}

IN an admirably clear-headed report, the Science Council of Canada has now recommended in principle the building of an intense neutron generator. A preliminary survey of the project, costing $\$ 7.5$ million, is to proceed forthwith. If this is favourable, present estimates call for a total of $\$ 155$ million to be spent by 1973 in building the generator.

The intense neutron generator will be based on a $1 \mathrm{GeV}$ proton linear accelerator. In $1952, \mathrm{~W}$. B. Lewis of the Canadian Chalk River Nuclear Laboratories realized the significance of certain experiments carried out with high energy protons from the cyclotron at Berkeley. These experiments implied that, in a thick target of heavy elements such as bismuth, each proton would generate many neutrons. The neutrons could be used to generate fissionable material by neutron capture in elements such as thorium. The uranium-233 thus produced, when burned in a reactor, might lead to the production of more electrical energy than was used originally to accelerate the electrons.

Apart from its possible relevance to low cost power production, the generator will be a valuable research tool in its own right. As the source of intense fluxes of thermal neutrons, it is expected to have applications in solid state physics, nuclear physics and materials science. It will also provide intense beams of neutrons, muons and pions for use in nuclear probes and elementary particle studies. An important industrial application will be the production of high-grade radioactive materials of commercial value. A breakdown of the various uses and purposes of the ING attributes about 60 per cent of its probable value to basic research and 40 per cent to applied research.

In making its recommendation, the Science Council of Canada has also taken explicit account of the nonscientific benefits to be expected from the generator. 
It points out that, for a country of Canada's size, a degree of specialization is essential if high standards arc to be achieved. Standards of excellence in given areas will not only encourage scientists and engineers to stay in Canada but also constitute the only sure way of achieving results which are internationally significant and competitive. The ING project is related to an area in which Canada already has an important investment and an international stature. It will have an encouraging effect on those concerned with the basic research and enginecring objectives of the project, and it is expected to have a substantial industrial fall-out. It does not duplicate research abroad, and should attract foreign scientists to Canada as well as placing Canada in a good position for exchanging research information with other countries.

\section{Control of Malaria}

The World Health Organization has been so successful in eradicating malaria from certain parts of the world (particularly in Europe, where the number of malarial cases fell from more than four million to less than seven thousand in the first fifteen years of WHO's existence) that it can now turn its attention to the problem of kceping these areas free of the disease. Unfortunately, laboratory tests for detecting potential malarial carriers are not completely effective, and a person infected by a mosquito may remain a carrier for a very long period of time. Permanent immigrants are more likely to re-introduce the disease than tourists, and the WHO technical report devoted to the problem stresses the necessity of co-operation between government authorities concerned with health and immigration. But it is possible to contract malaria during a short stay in an infected region, and the report recom. mends that shipping companies be aware of the problem, and that passengers and crews should be instructed in the use of prophylactics. A new difficulty besetting health workers has been the increase in the number of Plasmodia resistant to 4-aminoquinolines. Fortunately, however, few resistant strains have reached malaria-free countries; WHO hopes shortly to resume publication of its reports on the spread of the strains.

The measures Britain takes to keep out malaria are hardly exemplary. No checks for the disease are made on passengers coming from abroad--though the Board of Trade does issue advisory notices to shipping companies on the diagnosis and cure of the disease. Yet Britain has not been troubled by a malaria epidemic since 1921, and during the past ten years no cases have been reported. The reasons for this are partly fortuitous-Plasmodium falciparum does not usually survive in the mosquito long enough to be transferred to the next human host. This is not true of Plasmodium vivax, the malarial parasite endemic in Britain in the past but now imported by immigrants from India and Pakistan. Indian immigrants, however, tend to live in cities where the appropriate mosquito species are rare. In any case it appears that the mosquito population as a whole has been greatly diminished by farm insecticides-the use of which is not, of course, primarily directed against mosquitoes. Finally, as more and more people travel by air rather than by sea, the risk of passengers boing infected with malaria en route and entering Britain as innocent carriers of the disease has lessened. Not only do air passengers spend less time in infected areas, but aeroplanes and airports are rather easier to spray than ships and harbours.

\section{Tissues in Store}

THE problem of a Christmas present for the biologist who has everything might be solved by a glance at the catalogue of the Exotic Animal Tissue Bank. This is a collection of tissues which was established in September 1967 at the St. Louis Zoological Park, in St. Louis, Missouri, in co-operation with the Center for the Biology of Natural Systems at Washington University.

The tissues come from animals which have died in the zoo-the service operates as part of the zoo's research programme. There are now more than 1,000 specimens available to research workers, teachers and anyone else who would like them. Prices range from $\$ 2.00$ for $1-10 \mathrm{~g}$ to a minimum of $\$ 25.00$ for amounts greater than $1 \mathrm{~g}$. Prices for whole organs weighing less than $10 \mathrm{~g}$ will be quoted on application. With each specimen comes a brief history, including the species, age, sex, treatment given and cause of death. Many specimens have already been distributed to workers in a wide range of disciplines.

Specimens are fixed in 10 per cent buffered formalin, or frozen or made into slides, and it is hoped to expand the service to include fixation for elcctron microscopy. Anyone wanting to look at such things as the aorta of the sand boa constrictor, the spleen of the African lion, the rumen contents of the onyx, or the uterus of the agouti will now know where to apply.

\section{New Look for Classics}

"AN Approach through Classics" is a report prepared for the Schools Council on a possible course in the humanities for children between 11 and 14. In these three years, the children are to be given an account of events, myths, discoveries, literature, art, politics and personalities from the Egyptians and Sumerians to the Renaissance. Those who jib at the superficiality of learning implied by this syllabus could well reflect on how few "educated" people could give an account that was more than superficial on any topic within this huge range. What most people learn vaguely and by diffusion it is proposed to teach rather less vaguely, though necessarily with very little detail. But it is, perhaps, a pity that the syllabus makes no mention of any specialization, not because it would be good to induce in children the notion that human development has been a series of "set periods", but so as to point the dangers of generalization which such a course is prone to.

The course involves no study of any particular language nor - a more serious omission -any teaching of elementary linguistics. No one could expect fourtcen ycar olds to have enough Latin to be useful in understanding Roman life, but it might well have been profitable to make mention of language as a repository of culture. The use of translations in the study of classical literature, much emphasized in the report, will also bring problems. "Pupils very soon absorb Homeric style and diction, his similes, stock epithets, etc." - but is it useful to have children emulate cliches, even Homeric ones? The report quotes a splendid 